Article

\title{
Improving Estimation of Evapotranspiration under Water-Limited Conditions Based on SEBS and MODIS Data in Arid Regions
}

\author{
Chunlin Huang ${ }^{1, *}$, Yan $\mathrm{Li}^{1,2}$, Juan $\mathrm{Gu}^{3}$, Ling $\mathrm{Lu}^{1}$ and ${\mathrm{Xin} \mathrm{Li}^{1}}^{1,4}$ \\ Received: 28 September 2015; Accepted: 7 December 2015; Published: 10 December 2015 \\ Academic Editors: Yuei-An Liou, Qinhuo Liu, Magaly Koch and Prasad S. Thenkabail \\ 1 Key Laboratory of Remote Sensing of Gansu Province, Heihe Remote Sensing Experimental Research \\ Station, Cold and Arid Regions Environmental and Engineering Research Institute, Chinese Academy of \\ Sciences, Lanzhou 730000, China; liyan@lzb.ac.cn (Y.L.); luling@lzb.ac.cn (L.L.); lixin@lzb.ac.cn (X.L.) \\ 2 College of Resource and Environment, University of Chinese Academy of Sciences, Beijing 100101, China \\ 3 MoE Key Laboratory of West China's Environmental System, Lanzhou University, Lanzhou 730000, China; \\ gujuan@lzu.edu.cn \\ 4 CAS Center for Excellence in Tibetan Plateau Earth Sciences, Chinese Academy of Sciences, \\ Beijing 100101, China \\ * Correspondence: huangcl@lzb.ac.cn; Tel.: +86-931-496-7975; Fax: +86-931-827-9161
}

\begin{abstract}
This study proposes a method for improving the estimation of surface turbulent fluxes in surface energy balance system (SEBS) model under water stress conditions using MODIS data. The normalized difference water index (NDWI) as an indicator of water stress is integrated into SEBS. To investigate the feasibility of the new approach, the desert-oasis region in the middle reaches of the Heihe River Basin (HRB) is selected as the study area. The proposed model is calibrated with meteorological and flux data over 2008-2011 at the Yingke station and is verified with data from 16 stations of the Heihe Watershed Allied Telemetry Experimental Research (HiWATER) project in 2012. The results show that soil moisture significantly affects evapotranspiration (ET) under water stress conditions in the study area. Adding the NDWI in SEBS can significantly improve the estimations of surface turbulent fluxes in water-limited regions, especially for spare vegetation cover area. The daily ET maps generated by the new model also show improvements in drylands with low ET values. This study demonstrates that integrating the NDWI into SEBS as an indicator of water stress is an effective way to improve the assessment of the regional ET in semi-arid and arid regions.
\end{abstract}

Keywords: evapotranspiration; arid region; SEBS; remote sensing; MODIS; NDWI; Heihe River Basin

\section{Introduction}

Evapotranspiration (ET), which is the sum of soil surface evaporation and plant tissue transpiration, is an important energy exchange process of the soil-vegetation-atmosphere system that affects the redistribution of terrestrial surface radiation and precipitation [1]. Accurate estimations of land surface ET are important for studies on water resources and agricultural management, flood and drought monitoring, weather forecasting, and climate change. Traditional methods for measuring ET, such as the Bowen ratio, eddy correlation systems, aerodynamics, and soil water balance, can only obtain ET over small and homogeneous regions, and fluxes at large spatial scales are difficult to estimate [2]. For operational applications in agriculture, such as irrigation scheduling, water resource management, and drought monitoring, accurate regional variations in the surface fluxes, particularly $\mathrm{ET}$, are difficult to determine. 
Satellite remote sensing (RS) is an attractive tool for obtaining land surface information related to the energy and water balances, such as the albedo, land surface temperature (LST), leaf area index (LAI), and surface soil moisture. Therefore, RS data are ideally suited for deriving spatially-continuous fields of ET [2]. Over the last few decades, several methods have been proposed to estimate ET, which can be divided into three main categories: empirical approaches, physical models, and data assimilation [3]. Empirical approaches often apply statistical regression to estimate ET using the satellite vegetation index, LST, LAI, and other meteorological data [4-7]. Physical models can be classified into two types: surface conductance-based models and aerodynamic resistance-energy balance models [7]. Surface conductance-based models were developed from the Penman-Monteith (PM) combination equation, where the required surface conductance is estimated from the remotely sensed LAI using a biophysical model [8-10]. To overcome conductance parameterization problems, the Priestley-Taylor (PT) equation was developed, which simplified the PM equation by replacing the surface and aerodynamic resistance terms with an empirical multiplier $\alpha$ [11-13]. Aerodynamic resistance-energy balance models are based on the bulk resistance equation for heat transfer, the difference between the land surface temperature and the air temperature, and the aerodynamic resistance to turbulence heat transport [14]. The instantaneous latent heat flux can be estimated as a residual of the land surface energy balance equation. Depending on whether the soil and canopy are considered separately or together, these models can be divided into single-source and two-source models. Single-source models consider the land surface as a single system, while two-source models treat the land surface as a combination of soil and a canopy with variable turbulence fluxes. Examples of these models include the Surface Energy Balance Algorithm for Land (SEBAL) [15], the Simplified Surface Energy Balance Index (S-SEBI) [16], the Surface Energy Balance System (SEBS) [17], the satellite-based energy balance for Mapping Evapotranspiration with Internalized Calibration (METRIC) [18], and the Two-Source Energy Balance Model (TSEB) [19], which have been thoroughly discussed in a previous study [20]. Data assimilation is such a methods that can be used to combine land surface models and observations to accurately estimate ET on a continuous spatial and temporal scale [21-23]. Comparisons of different methods for estimating land surface fluxes at the local and global scales have demonstrated that the models have different degrees of success $[24,25]$.

This study focuses on SEBS, which calculates the sensible heat flux $(H)$ using a single-source bulk transfer equation and derives the evapotranspiration from the evaporative fraction [17]. Several studies have used SEBS to estimate land surface fluxes and ET with a wide range of sensors, such as the Advance Along-Track Scanning Radiometer (AATSR) [26], Advanced Spaceborne Thermal Emission and Reflection Radiometer (ASTER) [27,28], Medium Spectral Resolution Imaging Spectrometer (MERIS) [29], and Moderate Resolution Imaging Spectroradiometer (MODIS) [25,30-32]. In previous studies, the land surface fluxes estimated from SEBS were validated by a comparison with the observed Bowen ratio (BR) [31], eddy covariance (EC) [27,32], and Large Aperture Scintillometer (LAS) data [25,26,28].

Evapotranspiration is controlled by the availability of moisture and energy fluxes at the surface [24]. Under water-limited conditions, the available soil water limits ET. However, almost all empirical and physical models, including SEBS, lack a variable that directly estimates water stress. Several recent studies have integrated water stress into estimates of land surface evapotranspiration [14,31,33-35]. It has been found that water stress would underestimate the sensible heat flux and overestimate ET in SEBS models in semi-arid and arid regions $[27,31,36]$. To deal with this limitation, Gokmen et al. [31] explicitly integrated soil moisture information as a water stress index through a modified definition of $k B^{-1}$, which is the parameter that summarizes the excess aerodynamic resistance to heat transfer compared with momentum transfer. However, the surface turbulent fluxes and ET are difficult to obtain at high spatial resolutions using this method due to the lack of soil moisture observations. 
To improve the estimates of surface turbulent flux and ET in SEBS under water stress conditions, we have proposed an alternative way to improve estimates of surface turbulent fluxes in SEBS under water stress conditions using MODIS data [37]. In our previous study, the normalized difference water index (NDWI) is integrated into SEBS as an indicator of water stress based on linear, exponential, and S-curve equations, which can reduce $k B^{-1}$ as water stress increases and can further decrease the latent heat flux and ET as the sensible heat flux increases. One site (Yingke station from the Watershed Allied Telemetry Experimental Research (WATER) project during 2008-2009 [38]) was used to calibrate and validate with meteorological and EC flux observations in a previous study. The results show that the proposed scheme can significantly improve the land surface flux estimation in the Yingke station under water stress condition and the performance of revised SEBS based on linear, exponential, and S-curve equations are same. Wu et al. [39] also integrated the soil moisture information into SEBS for improving irrigated crop water consumption estimation. In order to ensure that the proposed scheme can be applied under a wide range of vegetation coverage and environmental conditions, in this study, the proposed scheme (only the S-curve equation) is calibrated with observations at the Yingke station during 2008-2011 and is validated by observations from 16 stations of the Heihe Watershed Allied Telemetry Experimental Research (HiWATER) project in 2012 [40]. Only the S-curve equation is calibrated and validated on account of the conceptual framework for defining soil moisture regimes and the corresponding evapotranspiration regimes proposed by Seneviratne et al. [41] and the sigmoid function used by Gokmen et al. [31]. Furthermore, the modified SEBS model (hereafter referred to as SEBS-NDWI) was used to calculate the regional land surface fluxes and daily evapotranspiration in the study area.

\section{Data}

\subsection{Study Area}

The Heihe River Basin (HRB) is the second largest inland river basin in China, covering an area of approximately $143,000 \mathrm{~km}^{2}$. From upstream to downstream, the basin features glaciers, frozen soil, alpine meadows, forests, irrigated crops, riparian ecosystems, and deserts. The desert-oasis zone in the middle reach of the HRB, which is located between $100^{\circ} 14^{\prime} \mathrm{E}-100^{\circ} 32^{\prime} \mathrm{E}$ and $38^{\circ} 42^{\prime} \mathrm{N}-39^{\circ} 0^{\prime} \mathrm{N}$, is chosen as the study area (Figure 1). The central part of the study area is a typical irrigated crop ecosystem, in which the main crops are maize and wheat. The region surrounding the oasis is mainly sandy desert, desert steppe, and the Gobi desert. The annual average temperature is $2.8-7.6{ }^{\circ} \mathrm{C}$, and there are approximately 3000 to $4000 \mathrm{~h}$ of sunshine per year. The annual precipitation is approximately $100-250 \mathrm{~mm}$, but the potential evaporation is as high as $1200-1800 \mathrm{~mm}$. Comprehensive eco-hydrological experiments, such as the WATER [38] and HiWATER [40] projects, have successfully been performed in this region. Many satellite, airborne, and ground observations that are suitable for ET studies have been collected.

\subsection{Field Measurements}

The field measurements include meteorological data and flux data that were obtained during the WATER and HiWATER experiments. These stations are described in Table 1.

During the WATER experiment, the Yingke station was installed in the central area of the oasis, which is located within typical irrigated farmland of maize and wheat (Figure 1). An automatic meteorological station (AMS), eddy covariance (EC) system, and soil moisture and temperature measurement system (SMTMS) were installed at the station. A set of continuous observations were obtained from November 2007 to December 2011. In this study, the observations from 1 March to 31 October of 2008-2011 are used to calibrate the model parameters of the proposed SEBS-NDWI model. 


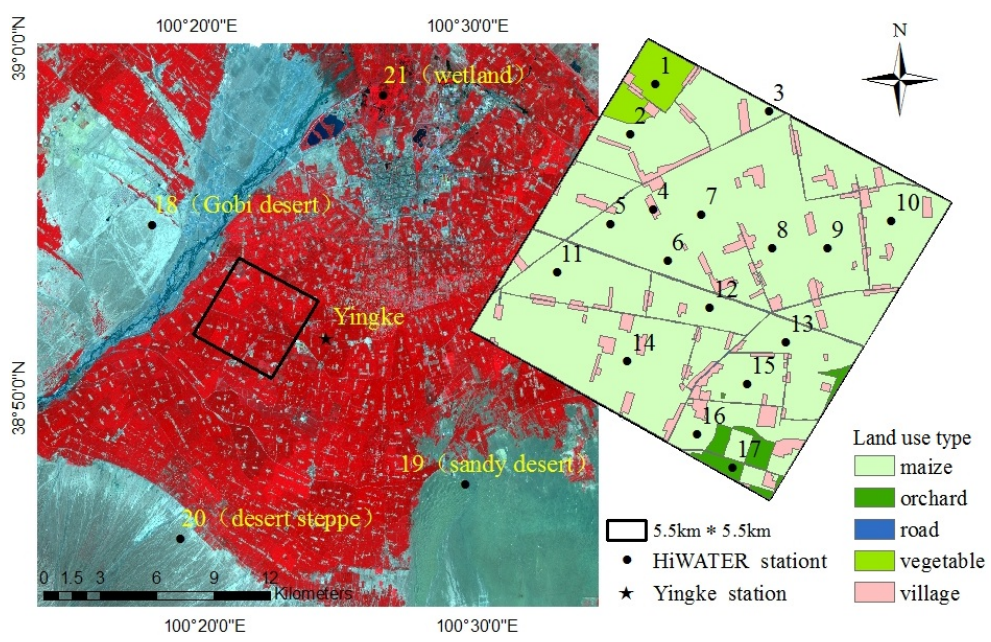

Figure 1. Spatial locations of the field observation stations in study area and land use map in the kernel experimental area.

Table 1. Description of observation stations in the WATER and HiWATER experiments.

\begin{tabular}{cccccc}
\hline Station & Longitude (E) & Latitude (N) & Elevation $(\mathbf{m})$ & Land Cover & Observation Period \\
\hline Yingke & 100.41033 & 38.85714 & 1519 & maize & $2007 / 11 / 5-2011 / 12 / 1$ \\
S1 & 100.35813 & 38.89322 & 1552 & vegetable & $2012 / 6 / 10-2012 / 9 / 17$ \\
S2 & 100.35406 & 38.88695 & 1559 & maize & $2012 / 5 / 3-2012 / 9 / 21$ \\
S3 & 100.37634 & 38.89053 & 1543 & maize & $2012 / 6 / 3-2012 / 9 / 18$ \\
S4 & 100.35753 & 38.87752 & 1561 & village & $2012 / 5 / 10-2012 / 9 / 17$ \\
S5 & 100.35068 & 38.87574 & 1567 & maize & $2012 / 6 / 4-2012 / 9 / 18$ \\
S6 & 100.35970 & 38.87116 & 1562 & maize & $2012 / 5 / 9-2012 / 9 / 21$ \\
S7 & 100.36521 & 38.87676 & 1556 & maize & $2012 / 5 / 28-2012 / 9 / 18$ \\
S8 & 100.37649 & 38.87254 & 1550 & maize & $2012 / 5 / 14-2012 / 9 / 21$ \\
S9 & 100.38546 & 38.87239 & 1543 & maize & $2012 / 6 / 4-2012 / 9 / 17$ \\
S10 & 100.39572 & 38.87567 & 1534 & maize & $2012 / 6 / 1-2012 / 9 / 17$ \\
S11 & 100.34197 & 38.86991 & 1575 & maize & $2012 / 6 / 2-2012 / 9 / 18$ \\
S12 & 100.36631 & 38.86515 & 1559 & maize & $2012 / 5 / 10-2012 / 9 / 21$ \\
S13 & 100.37852 & 38.86074 & 1550 & maize & $2012 / 5 / 6-2012 / 9 / 20$ \\
S14 & 100.35310 & 38.85867 & 1570 & maize & $2012 / 5 / 6-2012 / 9 / 21$ \\
S15 & 100.37223 & 38.85551 & 1556 & maize & $2012 / 5 / 10-2012 / 9 / 26$ \\
S16 & 100.36411 & 38.84931 & 1564 & maize & $2012 / 6 / 1-2012 / 9 / 17$ \\
S17 & 100.36972 & 38.84510 & 1559 & orchard & $2012 / 5 / 12-2012 / 9 / 17$ \\
S18 & 100.30420 & 38.91496 & 1562 & Gobi desert & $2012 / 5 / 13-2012 / 9 / 21$ \\
S19 & 100.49330 & 38.78917 & 1594 & sandy desert & $2012 / 6 / 1-2012 / 9 / 21$ \\
S20 & 100.31860 & 38.76519 & 1731 & desert steppe & $2012 / 6 / 2-2012 / 9 / 21$ \\
S21 & 100.44640 & 38.97514 & 1460 & wetland & $2012 / 6 / 25-2012 / 9 / 21$ \\
\hline
\end{tabular}

During the HiWATER experiment, a multi-scale observational experiment on evapotranspiration over heterogeneous land surfaces (MUSOEXE) was conducted from May to September 2012 [40,42]. Four AMSs were installed around the oasis (i.e., sandy desert, desert steppe, Gobi desert, and wetland stations); each station was supplemented with an EC system (Figure 1). An observation matrix composed of $17 \mathrm{EC}$ towers and ordinary AMSs were located within the oasis (i.e., the kernel experimental area covered an area of $5.5 \mathrm{~km} \times 5.5 \mathrm{~km}$, Figure 1), where the land surface is heterogeneous and is dominated by seed corn, corn interplanted with spring wheat, vegetables, orchards, and residential areas (Figure 1) [40]. Due to problems with the instruments, some of the observations at stations S3, S9, S10, S16, and S21 are missing, so the remaining observations from the 16 stations from 15 June to 15 September 2012, are used to validate the proposed SEBS-NDWI model.

The meteorological data (air temperature, humidity, wind speed, pressure, shortwave radiation, and longwave radiation) used in this study were obtained from AMS. Turbulent fluxes were measured by EC system with a sampling frequency $10-\mathrm{Hz}$. The raw high-frequency data were processed using EdiRe software developed by Edinburgh University, UK. Ground heat flux was 
measured by soil heat flux plates buried at a depth of $5 \mathrm{~cm}$ and $6 \mathrm{~cm}$, respectively, during the WATER experiment and HiWATER experiment. The meteorological data were recorded at $30 \mathrm{~min}$ interval during WATER experiment. The AMS in the HiWATER experiment recorded meteorological data at $10 \mathrm{~min}$ intervals, which were processed in $30 \mathrm{~min}$ interval. The turbulent fluxes from the EC system were processed at $30 \mathrm{~min}$ interval. The details of data processing can prefer to Liu et al. [43] and Liu et al. [44]. In this study, we excluded the data with energy balance closure of less than 0.75 . In addition, the Bowen ratio closure method was used to close the energy balance for turbulent fluxes from EC system [45].

\subsection{MODIS Land Data Products}

The MODIS land data products used in the study include surface reflectance in bands 1-7 and LST. These data are obtained from the online data pool at the NASA Land Processes Distributed Active Archive Center (LP DAAC), United States Geological Survey (USGS)/Earth Resources Observation and Science (EROS) Center, Sioux Falls, South Dakota. We choose the latest MOD09GA and MOD11A1 data, which provide bands 1-7 daily-gridded L2G Global $500 \mathrm{~m}$ reflectance values and the LST/E Daily L3 Global $1 \mathrm{~km}$ Grid product, respectively. We then use the MODIS Reprojection Tool (MRT) to reproject the original sinusoidal projection to a UTM projection with a WGS84 datum and a $500 \mathrm{~m}$ resolution.

\subsection{Normalized Difference Water Index}

The NDWI is defined as follows

$$
N D W I=\frac{\rho_{\mathrm{NIR}}-\rho_{\mathrm{SWIR}}}{\rho_{\mathrm{NIR}}+\rho_{\mathrm{SWIR}}}
$$

where $\rho_{\text {NIR }}$ and $\rho_{\text {SWIR }}$ represent the reflectances of the near-infrared and shortwave infrared bands, respectively, which correspond to band $2(841-876 \mathrm{~nm})$ and band $7(2105-2135 \mathrm{~nm})$ in MODIS images [46]. A positive correlation has been found between the NDWI and vegetation water content [47], so the NDWI is a useful indictor of vegetation water stress.

\section{Method}

SEBS was developed to estimate surface turbulent fluxes and daily evapotranspiration using remote sensing data [17]. The details of the original SEBS formulation can be found in references $[17,48]$. In this section, we first provide a short theoretical overview of SEBS and then describe how to integrate the NDWI into SEBS to address water stress in sparsely-vegetated semi-arid and arid regions.

\subsection{Surface Energy Balance System (SEBS)}

\subsubsection{Surface Energy Balance Terms}

The surface energy balance is usually written as

$$
R_{n}=G+H+\lambda E
$$

where $R_{n}$ is the net radiation, $G$ is the soil heat flux, $H$ is the sensible heat flux, and $\lambda E$ is the latent heat flux. In SEBS, $\lambda E$ is commonly calculated as the residual of the surface energy balance:

$$
\lambda E=R_{n}-H-G
$$

The net radiation $\left(R_{n}\right)$ is given by:

$$
R_{n}=(1-\alpha) R_{s w d}+\varepsilon R_{l w d}-\varepsilon \delta T_{s}^{4}
$$


where $R_{s w d}$ and $R_{l w d}$ are the downward solar radiation and longwave radiation, respectively, which obtained from AMSs; $\alpha$ and $\varepsilon$ are the albedo and emissivity of the land surface, respectively, $\delta$ is the Stefan-Boltzmann constant, and $T_{\mathrm{S}}$ is the surface temperature.

The soil heat flux is usually controlled by $R_{n}$ and is affected by the fraction of canopy cover, which is parameterized as:

$$
G=R_{n}\left[\Gamma_{c}+\left(1-f_{c}\right)\left(\Gamma_{s}-\Gamma_{c}\right)\right]
$$

where $f_{c}$ is the fraction of canopy cover, $\Gamma_{c}=0.05$ for a full vegetation canopy, and $\Gamma_{s}=0.315$ for bare soil.

\subsubsection{Calculation of Sensible Heat Flux}

The sensible heat flux is obtained iteratively by solving the set of nonlinear equations shown below, which were derived in part from the Monin-Obukhov similarity theory:

$$
\begin{gathered}
u=\frac{u_{*}}{k}\left(\ln \left(\frac{z-d_{0}}{z_{0 m}}\right)-\psi_{m}\left(\frac{z-d_{0}}{L}\right)+\psi_{m}\left(\frac{z_{0 m}}{L}\right)\right) \\
\theta_{0}-\theta_{a}=\frac{H}{k u_{*} \rho C_{p}}\left[\ln \left(\frac{z-d_{0}}{z_{0 h}}\right)-\psi_{h}\left(\frac{z-d_{0}}{L}\right)+\psi_{h}\left(\frac{z_{0 h}}{L}\right)\right] \\
L=-\frac{\rho C_{p} u_{*} \theta_{v}}{k g H} L=-\frac{\rho C_{p} u_{*}^{3} \theta_{v}}{k g H}
\end{gathered}
$$

where $Z$ is the height above the surface, $\mu$ is the wind speed, $u_{*}$ is the friction velocity, $k=0.4$ is von Karman's constant, $d_{0}$ is the zero plane displacement, $\rho$ is the air density, $C_{p}$ is the specific heat of air at a constant pressure, $z_{0 m}$ and $z_{0 h}$ are the roughness heights for momentum and heat transfer, respectively, $\psi_{m}$ and $\psi_{h}$ are the stability correction functions for momentum and heat transfer, respectively, $\theta_{a}$ is the potential temperature at the height $z, \theta_{0}$ is the potential temperature at the surface, $L$ is the Obukhov length, $\theta_{v}$ is the virtual temperature near the surface, and $g$ is the acceleration due to gravity.

\subsubsection{Calculation of Roughness Length for Heat Transfer}

The roughness length for heat transfer can be derived from:

$$
z_{0 h}=z_{0 m} / \exp \left(k B^{-1}\right)
$$

where $B^{-1}$ is the inverse Stanton number, which is a dimensionless heat transfer coefficient. SEBS uses a physically-based model to calculate $k B^{-1}$ [48], which is expressed as:

$$
k B^{-1}=\frac{k C_{d}}{4 C_{t} \frac{u_{*}}{u(h)}\left(1-e^{-n_{e c} / 2}\right)} f_{c}^{2}+\frac{k \frac{u_{*}}{u(h)} \frac{z_{0 m}}{h}}{C_{t}^{*}} f_{c}^{2} f_{s}^{2}+k B_{s}^{-1} f_{s}^{2}
$$

where $f_{s}=1-f_{c}$ is the fraction of soil coverage; $C_{d}$ is the drag coefficient of the foliage elements, which is assumed to have a value of $0.2 ; C_{t}$ is the heat transfer coefficient of the leaf, which has values of $0.005 \mathrm{~N} \leqslant C_{t} \leqslant 0.075 \mathrm{~N}$ ( $\mathrm{N}$ is the number of sides of a leaf that participate in the heat exchange); $h$ is the height of the vegetation canopy; $n_{e c}$ is the within-canopy wind speed profile extinction coefficient; $u(h)$ is the horizontal wind speed at the canopy height; $C_{t}^{*}$ is the heat transfer coefficient of the soil; and $k B_{s}^{-1}$ is the value for the bare soil surface given by Brutsaert [49]:

$$
k B_{S}^{-1}=2.46\left(\operatorname{Re}_{*}\right)^{1 / 4}-\ln (7.4)
$$

where $\mathrm{Re}_{*}$ is the roughness Reynolds number. 


\subsubsection{Calculation of Daily ET}

The daily ET is more applicable than the instantaneous ET and turbulent flux in hydrology and meteorology. Several methods have been developed to scale daily ET from instantaneous ET at the time of the satellite overpass. These methods are based on the assumption of diurnal self-preservation of the evaporative fraction $(E F)$ [50-53]. The $E F$ is defined as the ratio of the actual evaporation to the available energy (i.e., the difference between $R_{n}$ and $G$ ):

$$
\Lambda=\frac{\lambda E}{R_{n}-G}
$$

where $\Lambda$ is the evaporative fraction.

In this study, we use the following scheme to calculate the daily ET. First, the evaporative fraction is evaluated according to SEBS [17]:

$$
\Lambda=\frac{\Lambda_{r} \lambda E_{w e t}}{R_{n}-G}
$$

where $\lambda E_{\text {wet }}$ is the latent heat flux at the wet limit, and $\Lambda_{r}$ is the relative evaporative fraction:

$$
\Lambda_{r}=1-\frac{H-H_{\text {wet }}}{H_{d r y}-H_{\text {wet }}}
$$

where $H_{d r y}$ is the sensible heat flux at the dry limit. The estimation of $\lambda E_{w e t}$ and $H_{d r y}$ is described in [17].

Second, the daily net radiation is derived from:

$$
R_{n \_d a i l y}=R_{n s \_d a i l y}-R_{n l \_d a i l y}
$$

where $R_{n \_ \text {daily }}$ is the daily net radiation, and the daily net shortwave radiation $R_{n s \_d a i l y}$ [54]:

$$
\begin{gathered}
R_{n s \_d a i l y}=(1-\alpha)\left(a_{s}+b_{s} \frac{n}{N}\right) W_{d} \\
W_{d}=\frac{24}{\pi}\left(\frac{1}{\rho_{0}}\right)^{2} I_{0}\left(\omega_{0} \sin \varphi \sin \delta+\cos \varphi \cos \delta \sin \omega_{0}\right)
\end{gathered}
$$

where $W_{d}$ is the daily solar radiance; $a_{s}, b_{s}$ and the fraction of insolation $n / N(0.7$ in June, 0.67 in July, 0.65 in August, and 0.7 in September are used in this study [55]) are empirical coefficients used to perform the atmospheric correction; $\left(\frac{1}{\rho_{0}}\right)^{2}$ is the eccentricity correction; $I_{0}$ is the solar constant; $\omega_{0}$ is the sunrise angle; and $\varphi$ and $\delta$ are the latitude and the solar declination, respectively. Brunt [56] introduced an empirical parameterization of the daily net longwave radiation $R_{n l}$ daily that is based on the air temperature, humidity and the fraction of insolation:

$$
R_{n l \_d a i l y}=\varepsilon \sigma T_{a}^{4}\left(a-b \sqrt{e_{d}}\right)\left(c+d \frac{n}{N}\right)
$$

where $e_{d}$ is the actual vapor pressure, and $T_{a}$ is the air temperature, which is obtained from AWSs. Depending on the climatic conditions, the empirical coefficients of $a, b, c$, and $d$ can vary. In a continental climate, $a, b, c$, and $d$ equal $0.39,0.058,0.1$, and 0.9 , respectively.

The daily ET is finally given by:

$$
E T_{\text {daily }}=\frac{\Lambda \cdot R_{n_{-} \text {daily }}}{\lambda}
$$

where $E T_{\text {daily }}$ is the daily ET (mm), and $\lambda$ is the latent heat of vaporization. 


\subsubsection{Parameterization of Land Surface Parameters}

The necessary parameters of SEBS can be divided into two categories: (1) surface parameters, which include the surface temperature $T_{\mathrm{s}}$, the surface albedo $\alpha$, the surface emissivity $\varepsilon$, the fraction of canopy cover $f_{c}$, the leaf area index $L A I$, and the height of the vegetation canopy $h$, based on MODIS data; and (2) the meteorological parameters, which include the air temperature $T_{a}$, the barometric pressure $p$, the wind speed $u$, the specific humidity, the downward solar radiation $R_{s w d}$, and the downward longwave radiation $R_{l w d}$, measured by the AMS.

The $f_{c}, L A I$, and $h$ are useful indicators for monitoring the condition of the land surface and plant health and are expressed as functions of the NDVI [57]:

$$
\begin{gathered}
f_{c}=\left(\frac{N D V I-N D V I_{\min }}{N D V I_{\max }-N D V I_{\min }}\right)^{2} \\
L A I=N D V I \sqrt{\frac{1+N D V I}{1-N D V I}} \\
h=h_{\min }+\left(h_{\max }-h_{\min }\right) \frac{N D V I-N D V I_{\min }}{N D V I_{\max }-N D V I_{\min }} \\
N D V I=\frac{\rho_{N I R}-\rho_{R}}{\rho_{N I R}+\rho_{R}}
\end{gathered}
$$

where $N D V I_{\min }$ and $N D V I_{\max }$ are the maximum and minimum NDVI values in the study area, respectively ( 0.05 and 0.87 were used in this study); $h_{\min }$ and $h_{\max }$ are the $h$ values for bare soil and full vegetation, respectively $\left(0.0012 \mathrm{~m}\right.$ and $2 \mathrm{~m}$ were used in this study); and $\rho_{\text {NIR }}$ and represent the reflectance of the near-infrared and the red bands, respectively, which corresponds to band 2 $(841-876 \mathrm{~nm})$ and band $1(620-670 \mathrm{~nm})$ in MODIS images. The estimation approach of $f_{c}, L A I$, and $h$ were validated with ground measured data from HiWATER experiment in this study area. The determination coefficient $\left(\mathrm{R}^{2}\right)$ between estimated parameters (i.e., $f_{c}, L A I$, and $h$ ) and measured data are $0.71,0.67$, and 0.73 , respectively, which indicated that these functions can be used to estimate $f_{c}$, $L A I$, and $h$ in this region.

The surface albedo is used to estimate the amount of incident solar radiation that is reflected back to space; it greatly influences the surface energy budget and partitioning. Liang [58] proposed the narrowband-broadband conversion method for surface albedo using MODIS data:

$$
\alpha=0.160 \rho_{1}+0.291 \rho_{2}+0.243 \rho_{3}+0.116 \rho_{4}+0.112 \rho_{5}+0.081 \rho_{7}-0.0015
$$

where $\rho_{i}(i=1-5,7)$ represents the corresponding MODIS band surface reflectance values.

The surface emissivity is calculated by weighing the vegetation emissivity $\varepsilon_{c}$ and soil emissivity $\varepsilon_{s}$ according to their proportions in a pixel $[26,59,60]$ :

$$
\varepsilon=\varepsilon_{c} f_{\mathcal{c}}+\varepsilon_{s}\left(1-f_{c}\right)+4<d \varepsilon>f_{c}\left(1-f_{c}\right)
$$

where $\varepsilon_{c}=0.985$ for full vegetation and $\varepsilon_{s}=0.96$ for bare soil, and $\langle d \varepsilon>$ is a regional representative value that ranges from 0.00 to 0.02 ( 0.02 in this case).

\section{2. $k B^{-1}$ Parameterization Scheme}

In SEBS, provided that $z_{0 m}$ remains constant, a decrease in $k B^{-1}$ leads to decreased latent heat flux and ET as the sensible heat flux increases. Gokmen et al. [31] proposed an explicit integration of soil moisture information as a water stress index through a modified definition of $k B^{-1}$ in SEBS, which affects the exchange of sensible and latent heat between the canopy and the atmosphere. However, the surface turbulent fluxes and ET are difficult to obtain at high spatial resolutions using the method due to the lack of soil moisture observations. The NDWI was proposed by Gao [46] to detect the 
moisture conditions of vegetation canopies over large areas [4,47]. Significant positive correlations have also been found between the NDWI and EF which is shown in Section 4.1. Therefore, the $k B^{-1}$ parameterization scheme [31] is adopted but the water stress index is replaced by NDWI in this study. The specific method used to modify the value of $k B^{-1}$ in SEBS is expressed as:

$$
\begin{gathered}
k B_{N D W I}^{-1}=f \times k B^{-1} \\
f=a+\frac{1}{1+\exp (b-c \times N D W I)}
\end{gathered}
$$

where $k B_{N D W I}^{-1}$ is the modified $k B^{-1}$ value, which indicates the level of water stress; $f$ is a scaling factor, which is represented by a sigmoid function; and $a, b$, and $c$ are the coefficients of the sigmoid function, which can be derived from an optimization (e.g., the Shuffled Complex Evolution Algorithm-University of Arizona (SCE-UA) [61] by reducing the error between the EC observations and the SEBS estimates of sensible heat flux.

\section{Results}

\subsection{Influence of Soil Moisture on Evaporative Fraction}

Many authors have examined the influence of soil water availability on evapotranspiration by determining the relationship between soil moisture and evapotranspiration in different regions and soil types, land cover and scales. Positive correlations have been used when the soil water availability is insufficient [62-64]. Consistent with earlier studies, a positive correlation was found between the near-surface soil moisture $(S M)$ and the $E F$ at the Yingke station during the WATER experiment in 2008-2011 (Figure 2a) and at sixteen stations of the HiWATER experiment in 2012 (Figure 2b). The $S M$ is less than or equal to $0.3 \mathrm{~m}^{3} / \mathrm{m}^{3}$. The $E F$ increases with an increase in $S M$ until the $S M$ is greater than $0.3 \mathrm{~m}^{3} / \mathrm{m}^{3}$. When the soil water availability is sufficiently high (i.e., $S M$ is greater than $0.3 \mathrm{~m}^{3} / \mathrm{m}^{3}$ ), ET is controlled by the available radiant energy, and the effect of soil moisture on ET is not significant.
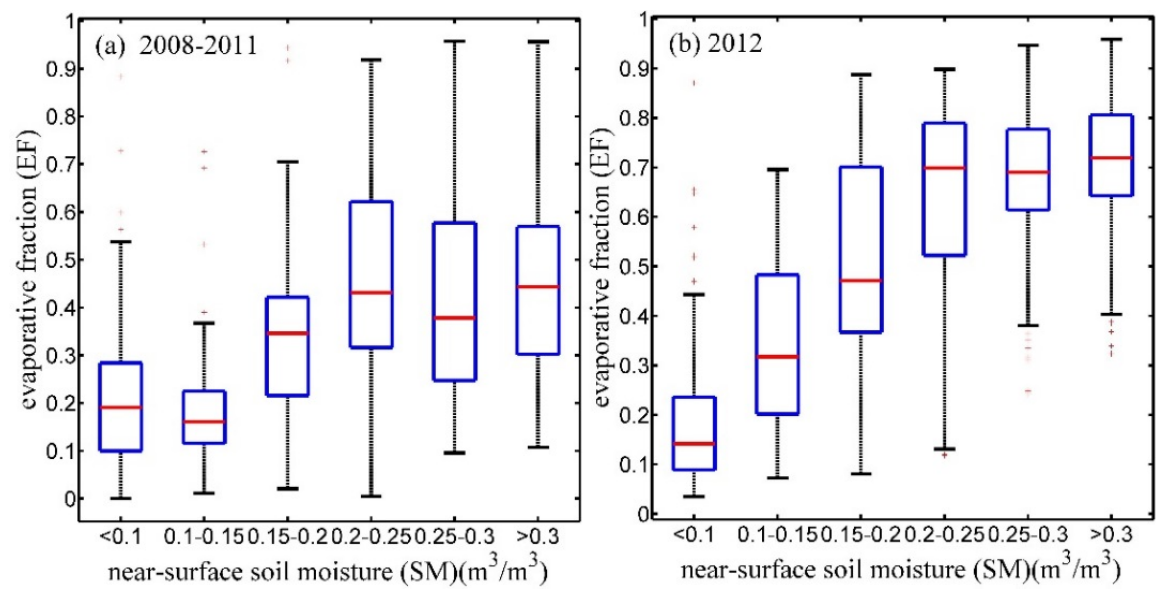

Figure 2. Box and whisker plots of near-surface soil moisture (SM) and evaporative fraction (EF) at (a) the Yingke station during the WATER experiment (2008-2011) and (b) sixteen stations of the HiWATER experiment (2012). SM denotes the daily average values of soil moisture measurements at a $5 \mathrm{~cm}$ depth, and $\mathrm{EF}$ is the evaporative fraction of the clear-sky daytime averages of the EC measurements.

In this case, we propose an explicit integration of NDWI as a water stress index into SEBS through a modified definition of $k B^{-1}$. The scatter plots between the NDWI and $E F$ at the Yingke station over 2008-2011 (Figure 3a) and at sixteen HiWATER stations in 2012 (Figure 3b) indicate 
significant positive correlations between the NDWI and $E F$, with determination coefficients of 0.62 and 0.75 , respectively.
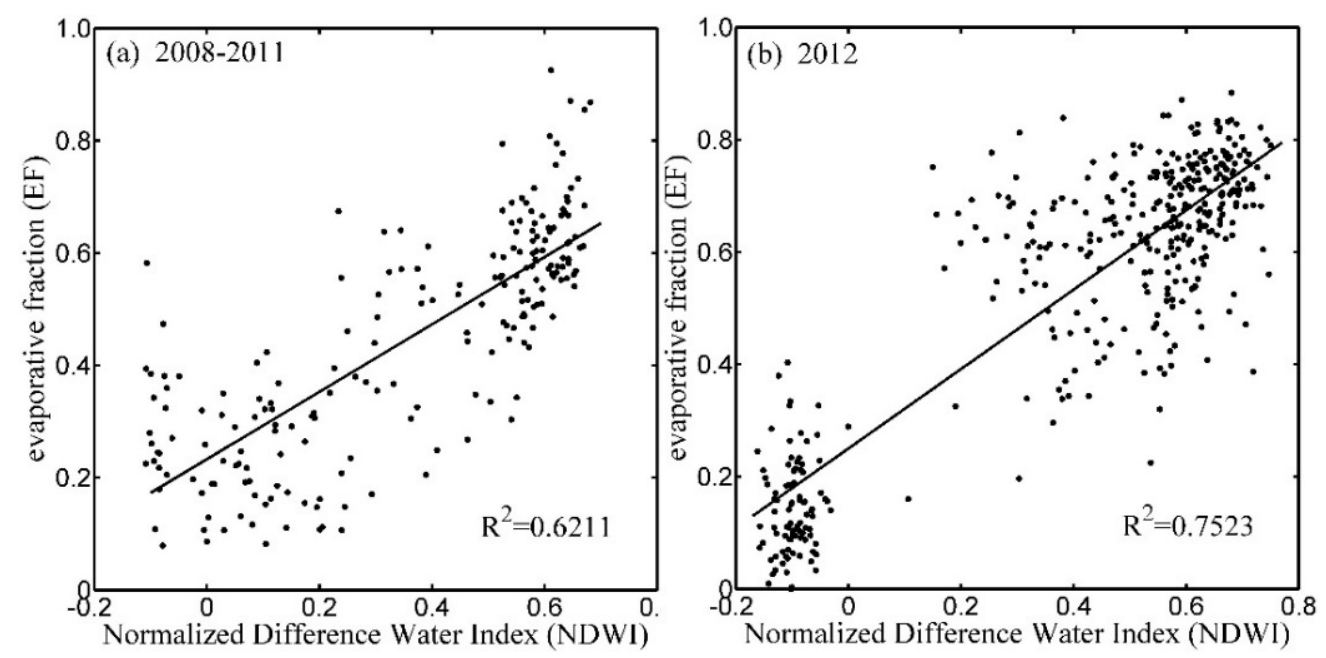

Figure 3. Relationships between the normalized difference water index (NDWI) and evaporative fraction (EF) at (a) the Yingke station during the WATER experiment (2008-2011) and (b) sixteen HiWATER stations (2012). EF is the evaporative fraction of the clear-sky daytime averages of the EC measurements.

\subsection{Calibration of SEBS-NDWI}

Generally, the spatial representativeness of EC is hundreds of meters, which is affected by the instruments heights of EC [3]. In this study, estimations of the single pixel where the EC station located is taken to be compared with measurements from EC. To obtain the coefficients of the sigmoid function (Equation (27)), we calibrated SEBS-NDWI using EC flux observations at the Yingke station (2008-2011) according to the scheme proposed in Section 3.2. The coefficients of $a, b$, and $c$ were $-0.47,0$, and 8.97, respectively. During early March to early May, the Yingke station is near bare because maize is usually cultivated in later April and the vegetative emergence of maize begin in early May. With the growth of maize, the surface is covered by vegetation gradually. After July, the maize grow up and enter into reproductive stage, the surface is covered with full vegetation. Maize harvesting in later September leaded to the Yingke station stand in spare vegetation areas. Owing to the seasonal diversity in vegetation coverage and environment conditions, the coefficients obtained by using Yingke Station are reasonable.

Furthermore, the observed surface turbulent fluxes from the EC system were compared with the modeled values of $H$ and $\lambda E$ from the original SEBS (Figure $4 a, c)$ and the SEBS-NDWI (Figure $4 \mathrm{~b}, \mathrm{~d}$ ). Consistent with earlier studies [27,31,33], the original SEBS clearly underestimated $H$ (Figure 4a), particularly for low values of the NDWI; therefore, a shortage of soil water and a lack of vegetation cover were present. Underestimation of $H$ leads to an overestimation of $\lambda E$ (Figure $4 \mathrm{c}$ ). The estimates of $H$ from the NDWI-integrated SEBS $\left(H_{S E B S}-N D W I\right)$ are closer to the EC observations $\left(H_{0}\right)$ for high values of $H_{0}$ compared with the estimates of $H$ from the original SEBS ( $H_{S E B S}$ ) (Figure $4 \mathrm{~b}$ ). Therefore, more EC and SEBS-NDWI point pairs are located near the 1:1 line in the scatter plot of $\lambda E$ (Figure 4d). The proposed scheme improves the underestimation of $H$ when the NDWI is less than or equal to 0.28 (the median of the NDWI); it also works well when the NDWI is greater than 0.28 (Figure $4 a, b$ ). 



Figure 4. Comparison of the modeled and observed surface turbulent fluxes at the Yingke station in 2008-2011. (a) and (b) show scatter plots of the measured and observed sensible heat fluxes from the original SEBS and the NDWI-integrated SEBS, respectively; (c) and (d) show scatter plots of the measured and observed latent heat fluxes from the original SEBS and the NDWI-integrated SEBS, respectively.

To assess the effect of integrating the NDWI into SEBS, the RMSE and BIAS values for SEBS and SEBS-NDWI are compared based on the EC-observed surface turbulent fluxes (Table 2). The results show an overall improvement in the modeled values of $H$ and $\lambda E$, with a $10 \mathrm{~W} / \mathrm{m}^{2}$ reduction in the RMSE and a $20 \mathrm{~W} / \mathrm{m}^{2}$ reduction in the BIAS when the NDWI is incorporated into SEBS. A significant improvement, with a large reduction in the RMSE and a 50\% reduction in the BIAS, occurs when the NDWI is less than or equal to 0.28 . When the NDWI is greater than 0.28 , the RMSEs between the SEBS-estimated surface turbulent fluxes and the SEBS-NDWI-estimated surface turbulent fluxes are mostly less than $8 \mathrm{~W} / \mathrm{m}^{2}$, which indicates that SEBS-NDWI results are similar to those of SEBS. The integration of NDWI into SEBS can significantly improve the estimates of surface turbulent fluxes under water-limited conditions, but the estimates of surface turbulent fluxes slightly change when adequate soil water is available. Under near-bare soil and sparse vegetation areas, the NDWI may potentially predicts soil moisture information, whereas it mainly index the moisture condition of vegetation rather than soil moisture content under the dense vegetation area. In the oasis area, the soil moisture content in the root zone of maize (depth at $10 \mathrm{~cm}-40 \mathrm{~cm}$ ) is mostly among $0.2 \mathrm{~m}^{3} / \mathrm{m}^{3}$ to $0.4 \mathrm{~m}^{3} / \mathrm{m}^{3}$, which is adequate for the consumption of maize. In other words, this area is under saturated moisture condition with higher NDWI value and vegetation moisture content and, thus, the evapotranspiration is controlled by the available energy rather than the soil moisture. This is the reason why the integration of NDWI into SEBS cannot refine the performance of the model when the pixels have high NDWI values.

Table 2. Error evaluations of the estimated sensible heat flux and latent heat flux from the original SEBS and the NDWI-integrated SEBS at the Yingke station (2008-2011).

\begin{tabular}{|c|c|c|c|c|c|c|c|c|c|c|c|c|}
\hline & \multicolumn{6}{|c|}{ Sensible Heat Flux (H) } & \multicolumn{6}{|c|}{ Latent Heat Flux $(\lambda E)$} \\
\hline & \multicolumn{3}{|c|}{$\operatorname{RMSE}\left(\mathrm{W} / \mathrm{m}^{2}\right)$} & \multicolumn{3}{|c|}{ BIAS $\left(\mathrm{W} / \mathrm{m}^{2}\right)$} & \multicolumn{3}{|c|}{ RMSE $\left(W / m^{2}\right)$} & \multicolumn{3}{|c|}{ BIAS $\left(W / m^{2}\right)$} \\
\hline & Overall & $\begin{array}{l}N D W I \\
\leqslant 0.28\end{array}$ & $\begin{array}{l}\text { NDWI } \\
>0.28\end{array}$ & Overall & $\begin{array}{l}N D W I \\
\leqslant 0.28\end{array}$ & $\begin{array}{c}N D W I \\
>0.28\end{array}$ & Overall & $\begin{array}{l}N D W I \\
\leqslant 0.28\end{array}$ & $\begin{array}{l}N D W I \\
>0.28\end{array}$ & Overall & $\begin{array}{l}N D W I \\
\leqslant 0.28\end{array}$ & $\begin{array}{l}\text { NDWI } \\
>0.28\end{array}$ \\
\hline SEBS & 91.2 & 127.4 & 55.7 & -52.4 & -110.8 & -13.9 & 122.2 & 149.1 & 100.6 & 95.1 & 131.5 & 71.0 \\
\hline SEBS-NDWI & 84.5 & 110.0 & 62.2 & -36.1 & -45.9 & -29.7 & 113.3 & 119.8 & 108.8 & 73.1 & 66.0 & 77.8 \\
\hline
\end{tabular}




\subsection{Validation of SEBS-NDWI}

The proposed scheme is validated with meteorological and flux data from 16 HiWATER stations in 2012. Figure 5 compares the modeled and observed surface turbulent fluxes at the 16 stations, and Table 3 shows the error evaluation of the surface turbulent fluxes from the original SEBS and NDWI-integrated SEBS based on EC observations. The modeled values of $H$ from the original SEBS $\left(H_{S E B S}\right)$ are clearly underestimated when the observed values of $H\left(H_{0}\right)$ are greater than $100 \mathrm{~W} / \mathrm{m}^{2}$ (Figure 5a), and the modeled values of $H$ from the NDWI-integrated SEBS $\left(H_{S E B S}-N D W I\right)$ are closer to $H_{0}$ for high values of $H_{0}$ (Figure 5c). When the NDWI is integrated into SEBS, the estimated values of $\lambda E$ decrease with as the estimated $H$ increases for low NDWI values. The estimated values of $\lambda E$ remain nearly unchanged for high NDWI values. The modeled $\lambda E$ clearly improves when the NDWI is included in SEBS; the RMSE and BIAS decrease by approximately $33 \mathrm{~W} / \mathrm{m}^{2}$ (Table 3). When the NDWI is less than or equal to 0.28 , the BIAS is $166.6 \mathrm{~W} / \mathrm{m}^{2}$ for $\lambda E$ calculated with the original SEBS or $23.7 \mathrm{~W} / \mathrm{m}^{2}$ for $\lambda E$ calculated with SEBS-NDWI. Thus, integrating the NDWI into SEBS avoids overestimating $\lambda E$ (Table 3). Overall, SEBS-NDWI tends to outperform the original SEBS, particularly under water-limited conditions.
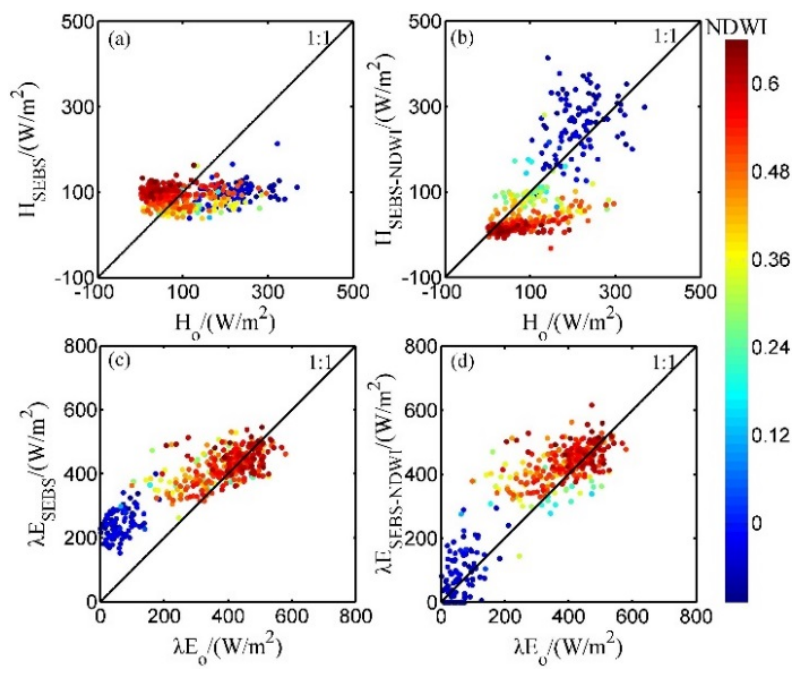

Figure 5. Comparison of modeled and observed surface turbulent fluxes at 16 stations in 2012. (a) and (b) show scatter plots of the measured and observed sensible heat fluxes from the original SEBS and the NDWI-integrated SEBS, respectively; (c) and (d) show scatter plots of the measured and observed latent heat fluxes from the original SEBS and the NDWI-integrated SEBS, respectively.

Table 3. Error evaluations of the estimated sensible heat flux and latent heat flux from the original SEBS and the NDWI-integrated SEBS at 16 stations in 2012.

\begin{tabular}{|c|c|c|c|c|c|c|c|c|c|c|c|c|}
\hline & \multicolumn{6}{|c|}{ Sensible Heat Flux (H) } & \multicolumn{6}{|c|}{ Latent Heat Flux $(\lambda E)$} \\
\hline & \multicolumn{3}{|c|}{$\operatorname{RMSE}\left(\mathrm{W} / \mathrm{m}^{2}\right)$} & \multicolumn{3}{|c|}{ BIAS $\left(\mathrm{W} / \mathrm{m}^{2}\right)$} & \multicolumn{3}{|c|}{ RMSE (W/m²) } & \multicolumn{3}{|c|}{ BIAS $\left(\mathrm{W} / \mathrm{m}^{2}\right)$} \\
\hline & Overall & $\begin{array}{l}N D W I \\
\leqslant 0.28\end{array}$ & $\begin{array}{l}N D W I \\
>0.28\end{array}$ & Overall & $\begin{array}{l}N D W I \\
\leqslant 0.28\end{array}$ & $\begin{array}{l}\text { NDWI } \\
>0.28\end{array}$ & Overall & $\begin{array}{l}N D W I \\
\leqslant 0.28\end{array}$ & $\begin{array}{l}N D W I \\
>0.28\end{array}$ & Overall & $\begin{array}{l}N D W I \\
\leqslant 0.28\end{array}$ & $\begin{array}{c}N D W I \\
>0.28\end{array}$ \\
\hline SEBS & 84.1 & 120.7 & 65.2 & -24.9 & -105.9 & 5.5 & 117.8 & 182.4 & 81.2 & 69.4 & 166.6 & 32.8 \\
\hline SEBS-NDWI & 79.8 & 92.5 & 74.4 & -25.3 & 45.1 & -51.8 & 84.1 & 76.6 & 86.7 & 37.6 & 23.7 & 42.8 \\
\hline
\end{tabular}

\subsection{Daily ET Mapping by SEBS-NDWI}

The main aim of this study is to improve the mapping of regional surface turbulent fluxes and evapotranspiration in arid regions with SEBS by integrating the NDWI, which is an indicator of water stress. We calculated the instantaneous sensible heat flux (Figure 6), the instantaneous latent heat flux (Figure 7) and the daily evapotranspiration (Figure 8) in the study area using the original SEBS and the NDWI-integrated SEBS models on 24 June, 10 July, 2 August and 3 September 2012. 
As shown in Figure 6, the spatial distribution of the sensible heat flux differs from the oasis to the desert areas. The instantaneous $H$ modeled by the original SEBS in the oasis ranges from $0 \mathrm{~W} / \mathrm{m}^{2}$ to $100 \mathrm{~W} / \mathrm{m}^{2}$, and the instantaneous $H$ modeled by SEBS in the area surrounding the oasis (sandy desert, desert steppe, and the Gobi desert) is clearly greater than that in the oasis $\left(100 \mathrm{~W} / \mathrm{m}^{2}\right.$ to $200 \mathrm{~W} / \mathrm{m}^{2}$ ) (Figure $6 \mathrm{a}-\mathrm{d}$ ). Figure $5 \mathrm{a}, \mathrm{b}$ show that the EC-observed values of $H$ range from $-50 \mathrm{~W} / \mathrm{m}^{2}$ to $400 \mathrm{~W} / \mathrm{m}^{2}$ in the study area at the times of the satellite overpasses from June to September. Clearly, SEBS underestimates $H$ when there is a shortage of soil water and a lack of vegetation coverage. In contrast, the estimates of $H$ from SEBS-NDWI are more similar to the EC observations, which range from $150 \mathrm{~W} / \mathrm{m}^{2}$ to $400 \mathrm{~W} / \mathrm{m}^{2}$ (Figure $6 \mathrm{e}-\mathrm{g}$ ). The difference between the estimates of $H$ on the four days is small, which indicates that no clear temporal variation occurs in the study area from June to September.

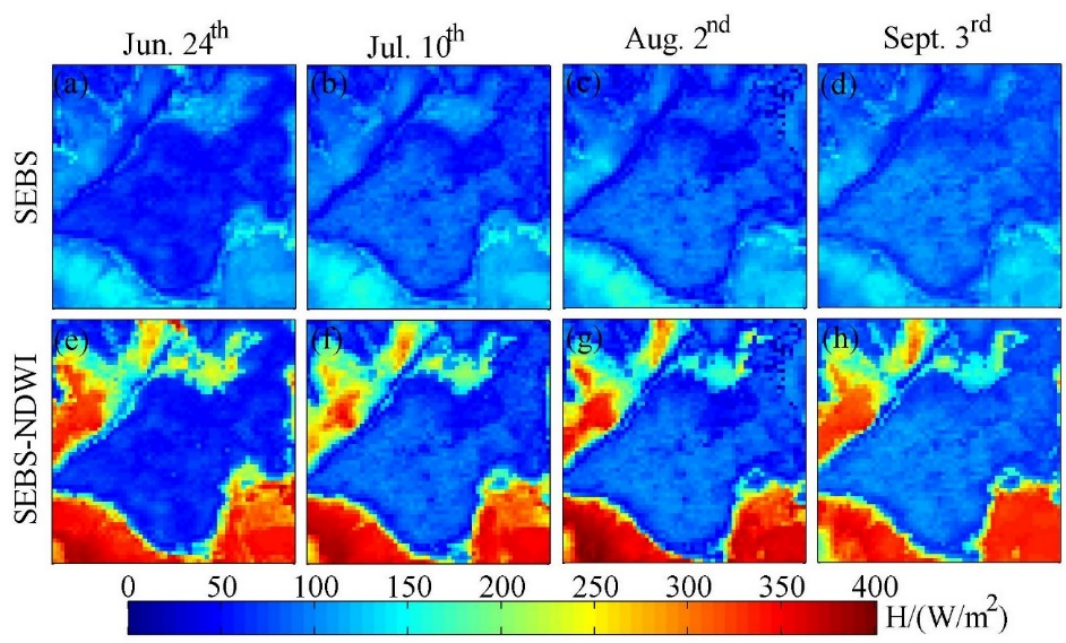

Figure 6. Instantaneous sensible heat flux maps of the study area in 2012. Figure 6 shows the instantaneous sensible heat flux maps obtained with the original SEBS for 24 June (a), 10 July (b), 2 August (c), and 3 September (d), respectively; and the instantaneous sensible heat flux maps obtained with the NDWI-integrated SEBS for 24 June (e), 10 July (f), 2 August (g), and 3 September (h), respectively.

The spatial distribution of the instantaneous latent heat flux also differed between the oasis and desert areas (Figure 7). The estimates of $\lambda E$ from SEBS range from $150 \mathrm{~W} / \mathrm{m}^{2}$ to $300 \mathrm{~W} / \mathrm{m}^{2}$ in the sandy desert, desert steppe, and Gobi desert, which lack soil water and vegetation cover (Figure 7a-d), while the EC-observed $\lambda E$ is less than $200 \mathrm{~W} / \mathrm{m}^{2}$ (Figure $5 \mathrm{~d}$ ). The $\lambda E$ values modeled by SEBS are greater than the observed $\lambda E$ values from EC under water-limited conditions. The estimates of $\lambda E$ from SEBS-NDWI are consistent with the EC-observed $\lambda E$ in the sandy desert, desert steppe, and Gobi desert, ranging from $0 \mathrm{~W} / \mathrm{m}^{2}$ to $200 \mathrm{~W} / \mathrm{m}^{2}$ (Figure 7e-h). $\lambda E$ exhibits a clear temporal variation in the oasis from June to September due to the changes in the vegetation coverage and radiation. With increasing vegetation coverage from June to August, more surface radiation energy is used to exchange water via transpiration. The estimation of $\lambda E$ in the oasis on 3 September is much lower than that on the other three days because of the reduction in the net radiation.

The spatial distribution of the daily evapotranspiration is identical to that of the latent heat flux. The daily ET in the oasis is considerably greater than that in the surrounding area (Figure 8). The daily ET modeled by SEBS ranges from $1.5 \mathrm{~mm} / \mathrm{d}$ to $4.0 \mathrm{~mm} / \mathrm{d}$ in the sandy desert, desert steppe, and Gobi desert. In contrast, when the NDWI is integrated into SEBS as an indicator of water stress, the model-produced daily ET values are less than $3 \mathrm{~mm} / \mathrm{d}$ in the sandy desert, desert steppe, and Gobi desert and are highly spatially variable from the oasis to the desert areas (Figure 8). Furthermore, the daily ET values that were modeled by SEBS-NDWI are greatly reduced in the arid and sparsely 
vegetated areas, while the high ET values for the oasis remain in the same range as those given by SEBS (Figure 8). A clear temporal variation in the daily ET occurs in the oasis from June to September due to the differences in vegetation coverage and solar radiance. The maximum values of the daily ET in the oasis are $5.88 \mathrm{~mm} / \mathrm{d}, 6.17 \mathrm{~mm} / \mathrm{d}, 6.41 \mathrm{~mm} / \mathrm{d}$, and $4.53 \mathrm{~mm} / \mathrm{d}$ on $24 \mathrm{June}, 10 \mathrm{July}, 2$ August, and 3 September, respectively (Figure 8e-h). In contrast, the temporal variation in the daily ET in the sandy desert, desert steppe, and Gobi desert is not apparent (Figure 8e-h).

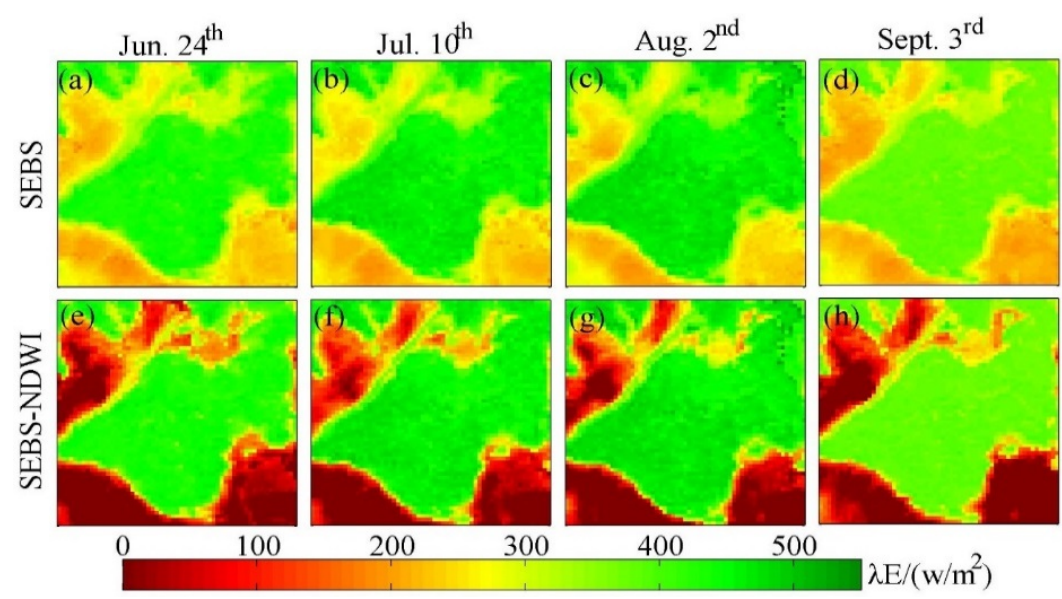

Figure 7. Instantaneous latent heat flux maps of the study area in 2012. Figure 7 show the instantaneous latent heat flux maps obtained with the original SEBS for 24 June (a), 10 July (b), 2 August (c), and 3 September (d), respectively; and the the instantaneous latent heat flux maps obtained with the NDWI-integrated SEBS for 24 June (e), 10 July (f), 2 August (g), and 3 September (h), respectively.

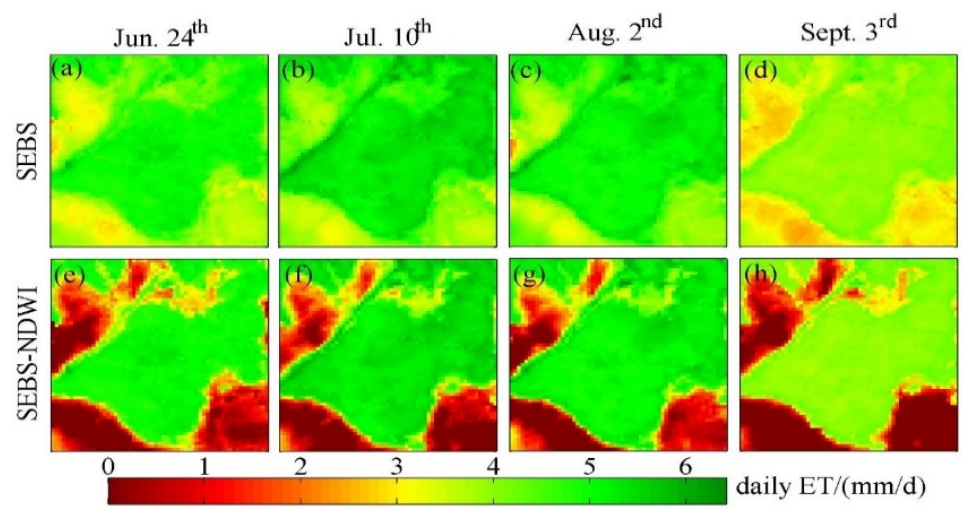

Figure 8. Daily evapotranspiration maps of the study area in 2012. Figure 8 show the daily evapotranspiration maps obtained with the original SEBS for 24 June (a), 10 July (b), 2 August(c), and 3 September (d), respectively; and the daily evapotranspiration maps obtained with the NDWI-integrated SEBS for 24 June (e), 10 July (f), 2 August (g), and 3 September (h), respectively.

To validate the estimated daily ET from the models, the modeled values of the daily ET from SEBS and SEBS-NDWI were compared with the observed daily ET (Figure 9). The original SEBS overestimated the observed low daily ET (Figure 9a) in villages, sandy deserts, desert steppes, and the Gobi Desert. The proposed model, which considers the influence of water stress on the evaporative fraction, improves the overestimation of the daily ET in these areas where the observed daily ET is less than $3 \mathrm{~mm} / \mathrm{d}$ (Figure $9 \mathrm{~b}$ ). The RMSE of the estimated daily ET decreases from $1.37 \mathrm{~mm} / \mathrm{d}$ to $1.09 \mathrm{~m} / \mathrm{d}$. The high daily ET values modeled by both SEBS and SEBS-NDWI are less than the observations (Figure 9); this result is likely due to underestimation of net radiation 
caused by mismatch of the spatial scale between observations and MODIS pixels (Figure 10). The observation towers in the oasis are located in center of farmland and the meteorological variables and turbulent fluxes are observed over homogenous crop or vegetable fields. However, the spatial resolution of MODIS products is $1 \mathrm{~km}$, which is usually mixed by vegetation and bare soil in this region. The land surface temperature and albedo are usually higher for bare soil than those for vegetation covered soil, which will cause that surface temperature and albedo derived from MODIS are higher than observations from towers in vegetation covered farmland. Therefore, the estimated net radiation will decrease due to the negative correlation between net radiation and land surface temperature and albedo according to Equation (4). Additionally, the self-preservation assumption of the $E F$ is not always valid under wet conditions. During the day time, the $E F$ of farmlands curve is concave upward shows that the $E F$ is higher in the early morning and later afternoon [65]. Using the $E F$ around noon to estimate daily ET may be another reason for the underestimation of daily ET. Furthermore, uncertainties of parameterization schemes related to vegetation also influence the estimation of daily ET.
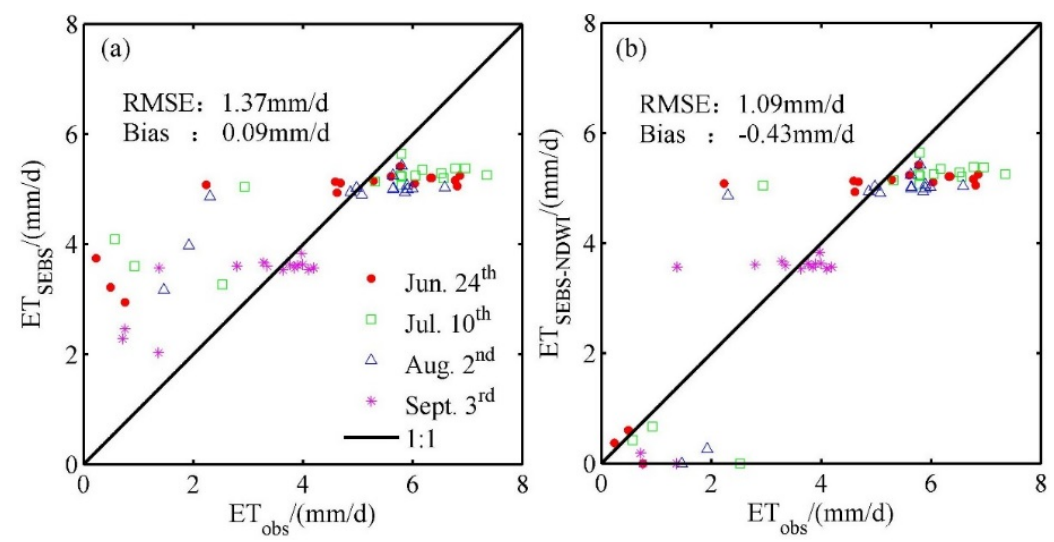

Figure 9. Comparison of modeled and observed daily evapotranspiration at 16 stations on 24 June, 10 July, 2 August, and 3 September, 2012. (a) and (b) are scatter plots of the daily observations of evapotranspiration and the results from the original SEBS and NDWI-integrated SEBS.



Figure 10. Comparison of modeled daily net radiation from SEBS and daily net radiation observed from the 16 AMSs on 24 June, 10 July, 2 August, and 3 September, 2012.

\section{Conclusions}

ET is mainly controlled by the available radiant energy and soil water. A positive correlation exists between the near-surface soil moisture and the evaporative fraction in regions with 
different land cover and climates, including the study area. However, SEBS, which estimates evapotranspiration from the energy balance, does not explicitly consider soil moisture when calculating land surface fluxes and ET, but it assumes that the soil moisture information is incorporated into the land surface temperature state variable. This assumption works well when the available radiant energy is the limiting factor for ET, but the ET is overestimated under water-limited conditions in semi-arid and arid regions.

In this study, we proposed an explicit integration of the NDWI as a water stress index into SEBS through a modified definition of $k B^{-1}$. Significant positive correlations exist between the NDWI and $E F$, with correlation coefficients of 0.62 and 0.75 , respectively, for the two sets of experimental data. Integrating the NDWI as an indicator of water stress into SEBS causes $k B^{-1}$ to decrease as the water stress increases and causes the latent heat flux and ET to decrease as the sensible heat flux increases. The modeled land surface fluxes improve when the NDWI is incorporated into SEBS, particularly for low values of the NDWI, where soil water and vegetation coverage are lacking. The proposed scheme not only significantly improves the estimation of surface turbulent fluxes under water-limited conditions but also provides good results when adequate soil water is available. The regional daily ET can also be reasonably estimated using only MODIS data products and meteorological data. The SEBS-NDWI method not only accurately captures the spatial distribution of the daily ET from the oasis to the desert areas but also represents the temporal variation in the daily ET in the oasis. However, the modeled values of the daily ET from SEBS and SEBS-NDWI are lower than the observations for high daily ET values because of the underestimation of the daily net radiation and the invalid self-preservation assumption of the $E F$.

The developed SEBS-NDWI scheme provides an effective method of estimating the regional ET in semi-arid and arid regions, and it only requires MODIS data products and meteorological data as inputs. The scheme effectively resolves the requirements of high spatial resolution soil moisture products in SEBS under water stress conditions [31]. However, the estimation of ET in dense vegetation areas should be improved, particularly because of the uncertainties in the parameterization schemes of the land surface parameters and daily net radiation, which are usually related to the study region and the selected sensors. Additionally, the developed SEBS-NDWI does not take effect in dense vegetation areas, because canopy density also influences the correlation between NDWI and EF. In other words, NDWI and other water stress indices present a strong correlation with structural indices (Normalized Difference Vegetation Index, such as NDVI) related to canopy density [66]. This correlation should be removed to capture the vegetation stress and it will be considered in future studies.

Acknowledgments: This work is supported by the National Science Foundation of China under grants 91325106 and 41271358, the Hundred Talent Program of the Chinese Academy of Sciences under grant 29Y127D01, and the Cross-disciplinary Collaborative Teams Program for Science, Technology and Innovation of the Chinese Academy of Sciences.

Author Contributions: Chunlin Huang designed the research approach and participated in the manuscript writing and revision. Yan Li performed the research and wrote the manuscript. Juan $\mathrm{Gu}$, Ling $\mathrm{Lu}$ and Xin Li participated in the design and revision of the manuscript.

Conflicts of Interest: The authors declare no conflict of interest.

\section{References}

1. Rivas, R.; Caselles, V. A simplified equation to estimate spatial reference evaporation from remote sensing based surface temperature and local meteorological data. Remote Sens. Environ. 2003, 93, 68-76. [CrossRef]

2. Courault, D.; Seguin, B.; Olioso, S. Review on estimation of evapotranspiration from remote sensing data: From empirical to numerical modeling approaches. Irrig. Drain. Syst. 2005, 19, 223-249. [CrossRef]

3. Jia, Z.Z.; Liu, S.M.; Xu, Z.W.; Chen, Y.J.; Zhu, M.J. Validation of remotely sensed evapotranspiration over the hai river basin, China. J. Geophys. Res. Atmos. 2012, 117, 110-117. [CrossRef] 
4. Jackson, J.T.; Chen, D.; Cosh, M.; Li, F.; Anderson, M.; Walthall, C.; Doriaswamy, P.; Hunt, E.R. Vegetation water content mapping using landsat data derived normalized difference water index for corn and soybeans. Remote Sens. Environ. 2004, 92, 475-482. [CrossRef]

5. Wang, K.; Wang, P.; Li, Z.; Cribb, M.; Sparrow, M. A simple method to estimate actual evapotranspiration from a combination of net radiation, vegetation index, and temperature. J. Geophys. Res. Atmos. 2007, 112, D15107. [CrossRef]

6. Wang, K.; Liang, S. An improved method for estimating global evapotranspiration based on satellite determination of surface net radiation, vegetation index, temperature, and soil moisture. J. Hydrol. 2008, 9 , 712-727.

7. Yan, H.; Wang, S.Q.; Billesbach, D.; Oechel, W.; Zhang, J.H.; Meyers, T.; Scott, R. Global estimation of evapotranspiration using a leaf area index-based surface energy and water balance model. Remote Sens. Environ. 2012, 124, 581-595. [CrossRef]

8. Cleugh, H.A.; Leuning, R.; Mu, Q.; Running, S.W. Regional evaporation estimates from flux tower and MODIS satellite data. Remote Sens. Environ. 2007, 106, 285-304. [CrossRef]

9. Mu, Q.; Heinsch, F.A.; Zhao, M.; Running, S.W. Development of a global evapotranspiration algorithm based on MODIS and global meteorology data. Remote Sens. Environ. 2007, 111, 519-536. [CrossRef]

10. Leuning, R.; Zhang, Y.Q.; Rajaud, A.; Cleugh, H.; Tu, K. A simple surface conductance model to estimate regional evaporation using MODIS leaf area index and the Penman-Monteith equation. Water Resour. Res. 2008, 44, W10419. [CrossRef]

11. Jiang, L.; Islam, S. A methodology for estimation of surface evapotranspiration over large areas using remote sensing observations. Geophys. Res. Lett. 1999, 26, 2773-2776. [CrossRef]

12. Fisher, J.B.; Tu, K.P.; Baldocchi, D.D. Global estimates of the land-atmosphere water flux based on monthly AVHRR and ISLSCP-II data, validated at 16 FLUXNET sites. Remote Sens. Environ. 2008, 112, 901-919. [CrossRef]

13. Venturini, V.; Islam, S.; Rodriguez, L. Estimation of evaporative fraction and evapotranspiration from MODIS products using a complementary based model. Remote Sens. Environ. 2008, 112, 132-141. [CrossRef]

14. García, M.; Sandholt, I.; Ceccato, P.; Ridler, M.; Mougin, E.; Kergoat, L.; Morillas, L.; Timouk, F.; Fensholt, R.; Domingo, F. Actual evapotranspiration in drylands derived from in situ and satellite data: Assessing biophysical constraints. Remote Sens. Environ. 2013, 131, 103-118. [CrossRef]

15. Bastiaanssen, W.G.M.; Menenti, M.; Feddes, R.A.; Holtslag, A.A.M. A remote sensing surface energy balance algorithm for land (SEBAL)—1. Formulation. J. Hydrol. 1998, 213, 198-212. [CrossRef]

16. Roerink, G.J.; Su, Z.; Menenti, M. S-SEBI: A simple remote sensing algorithm to estimate the surface energy balance. Phys. Chem. Earth B Hydrol. Oceans Atmos. 2000, 25, 147-157. [CrossRef]

17. Su, Z. The Surface Energy Balance System (SEBS) for estimation of turbulent heat fluxes. Hydrol. Earth Syst. Sci. 2002, 6, 85-99. [CrossRef]

18. Allen, R.G.; Tasumi, M.; Trezza, R. Satellite-based energy balance for mapping evapotranspiration with internalized calibration (METRIC)-Model. J. Irrig. Drain. Eng. ASCE 2007, 133, 380-394. [CrossRef]

19. Norman, J.M.; Kustas, W.P.; Humes, K.S. Source approach for estimating soil and vegetation energy fluxes in observations of directional radiometric surface temperature. Agric. For. Meteorol. 1995, 77, $263-293$. [CrossRef]

20. Lion, Y.A.; Kar, S.K. Evapotranspiration Estimation with Remote Sensing and Various Surface Energy Balance algorithms-A review. Energies 2014, 7, 2821-2847.

21. Caparrini, F.; Castelli, F.; Entekhabi, D. Estimation of surface turbulent fluxes through assimilation of radiometric surface temperature sequences. J. Hydrometeorol. 2004, 5, 145-159. [CrossRef]

22. Huang, C.L.; Li, X.; Wang, J.M.; Gu, J. Assimilation of remote sensing data products into common land model for evapotranspiration forecasting. In Proceedings of the 8th International Symposium on Spatial Accuracy Assessment in Natural Resources and Environmental Sciences, Shanghai, China, 25-27 June 2008.

23. Xu, T.R.; Liang, S.L.; Liu, S.M.; Zhu, X.F.; Tao, X. Estimating turbulent fluxes through assimilation of geostationary operational environmental satellites data using ensemble Kalman filter. J. Geophys. Res. 2011, 116, D09109. [CrossRef]

24. Tang, R.; Li, Z.L.; Jia, Y.; Li, C.; Sun, X.; Kustas, W.P.; Anderson, M.C. An intercomparison of three remote sensing-based energy balance models using Large Aperture Scintillometer measurements over a wheat-corn production region. Remote Sens. Environ. 2011, 115, 3187-3202. [CrossRef] 
25. Wang, Y.Y.; Li, X.; Tang, S.H. Validation of the SEBS-derived sensible heat for FY3A/VIRR and TERRA/MODIS over an alpine grass region using LAS measurements. Int. J. Appl. Earth Obs. 2013, 23, 226-233. [CrossRef]

26. Jia, L.; Su, Z.; Bart, H.; Menenti, M.; Moene, A.; de Bruin, H.A.R.; Javier, B.Y.J.; Ibanez, M.; Cuesta, A. estimation of sensible heat flux using the Surface Energy Balance System(SEBS) and ATSR measurements. Phys. Chem. Earth 2003, 28, 75-88. [CrossRef]

27. Ma, W.Q.; Ma, Y.M.; Hu, Z.Y.; Su, Z.; Wang, J.M.; Ishikawa, H. Estimation surface fluxes over middle and upper streams of the Heihe River Basin with ASTER imagery. Hydrol. Earth Syst. Sci. 2011, 15, 1403-1413. [CrossRef]

28. Kwast, J.; Timmermans, W.; Gieske, A.; Su, Z.; Olioso, A.; Jia, L.; Elbers, J.; Karssenberg, D.; de Jong, S. Evaluation of the Surface Energy Balance System (SEBS) applied to ASTER imagery with flux-measurements at the SPARC 2004 site (Barrax, Spain). Hydrol. Earth Syst. Sci. 2009, 13, 1337-1347. [CrossRef]

29. Elhag, M.; Psilovikos, A.; Manakos, I.; Perakis, K. Application of the SEBS water balance model in estimating daily evapotranspiration and evaporative fraction from remote sensing data over the Nile Delta. Water Resour. Manag. 2011, 25, 2731-2742. [CrossRef]

30. Alkhaier, F.; Su, Z.; Flerchinger, G.N. Reconnoitering the effect of shallow groundwater on land surface temperature and surface energy balance using MODIS and SEBS. Hydrol. Earth Syst. Sci. 2012, 16, 1833-1844. [CrossRef]

31. Gokmen, M.; Vekerdy, Z.; Verhoef, A.; Verhoef, A.; Batelaan, O.; Tol, C. Integration of soil moisture in SEBS for improving evapotranspiration estimation under water stress conditions. Remote Sens. Environ. 2012, 121, 261-274. [CrossRef]

32. Pardo, N.; Sánchez, M.L.; Timmermans, J.; Su, Z.; Pérez, I.A.; García, M. SEBS validation in a Spanish rotating crop. Agric. For. Meteorol. 2014, 195, 132-142. [CrossRef]

33. Miralles, D.G.; Holmes, T.R.H.; Jeu, R.A.M.; Gash, J.H.; Meesters, A.; Dolman, A.J. Global land-surface evaporation estimated from satellite-based observations. Hydrol. Earth Syst. Sci. 2011, 15, 453-469. [CrossRef]

34. Campos, I.; Villodre, J.; Carrara, A.; Calera, A.; Caleraa, A. Remote sensing-based soil water balance to estimate Mediterranean holm oak savanna (dehesa) evapotranspiration under water stress. J. Hydrol. 2013, 494, 1-9. [CrossRef]

35. Ding, R.H.; Kang, S.Z.; Li, F.H.; Zhang, Y.Q.; Tong, L. Evapotranspiration measurement and estimation using modified Priestley-Taylor model in an irrigated maize field with mulching. Agric. For. Meteorol. 2013, 168, 140-148. [CrossRef]

36. Ma, Y.F.; Liu, S.M.; Zhang, F.; Zhou, J.; Jia, Z.Z.; Song, L.S. Estimations of regional surface energy fluxes over heterogeneous oasis-desert surfaces in the middle reaches of the Heihe River during HiWATER-MUSOEXE. IEEE Geosci. Remote Sens. Lett. 2015, 12, 671-675.

37. Huang, C.L.; Li, Y.; Lu, L.; Gu, J. Estimation of surface fluxes under drought water stress conditions based on remotely sensed data. Adv. Water Sci. 2014, 25, 181-188. (In Chinese).

38. Li, X.; Li, X.W.; Li, Z.; Ma, M.; Wang, J.; Xiao, Q.; Liu, Q.; Che, T.; Chen, E.; Yan, G.; et al. Watershed allied telemetry experimental research. J. Geophys. Res. Atmos. 2009, 114, D22103. [CrossRef]

39. Wu, X.J.; Zhou, J.; Wang, H.J.; Li, Y.; Zhong, B. Evaluation of irrigation water use efficiency using remote sensing in the middle reach of the Heihe river, in the semi-arid northwestern China. Hydrol. Process. 2015, 29, 2243-2257. [CrossRef]

40. Li, X.; Cheng, G.; Liu, S.; Xiao, Q.; Ma, M.; Jin, R.; Che, T.; Liu, Q.; Wang, W.; Qi, Y.; et al. Heihe watershed allied telemetry experimental research (HiWATER): Scientific objectives and experimental design. Bull. Am. Meteorol. Soc. 2013, 94, 1145-1160. [CrossRef]

41. Seneviratne, S.I.; Corti, T.; Davin, E.L.; Hirschi, M.; Jaeger, E.B.; Lehner, I.; Orlowsky, B.; Teuling, A.J. Investigating soil moisture-climate interactions in a changing climate: A review. Earth-Sci. Rev. 2010, 99, 125-161. [CrossRef]

42. Xu, Z.W.; Liu, S.M.; Li, X.; Shi, S.J.; Wang, J.M.; Zhu, Z.L.; Xu, T.R.; Wang, W.; Ma, M. Intercomparison of surface energy flux measurement systems used during the HiWATER-MUSOEXE. J. Geophys. Res. 2013, 118, 13140-13157. [CrossRef] 
43. Liu, S.M.; Xu, Z.W.; Wang, W.Z.; Bai, J.; Jia, Z.; Zhu, M.; Wang, J.M. A comparison of eddy-covariance and large aperture scintillometer measurements with respect to the energy balance closure problem. Hydrol. Earth Syst. Sci. 2011, 15, 1291-1306. [CrossRef]

44. Liu, S.M.; Xu, Z.W.; Zhu, Z.L.; Jia, Z.Z.; Zhu, M.J. Measurements of evapotranspiration from eddy-covariance systems and large aperture scintillometers in the Hai River Basin, China. J. Hydrol. 2013, 487, 24-38. [CrossRef]

45. Twine, T.E.; Kustas, W.P.; Norman, J.M.; Cook, D.R.; Houser, P.R. Correcting eddy-covariance flux underestimation over a grassland. Agric. For. Meteorol. 2000, 103, 279-300. [CrossRef]

46. Gao, B.C. NDWI-A normalized difference water Index for remote sensing of vegetation liquid water from space. Remote Sens. Environ. 1996, 58, 257-266. [CrossRef]

47. Chen, D.Y.; Huang, J.F.; Thomas, J.J. Vegetation water content estimation for corn and soybeans using spectral indices derived from MODIS near and short-wave infrared bands. Remote Sens. Environ. 2005, 98, 225-236. [CrossRef]

48. Su, Z.; Schmugge, T.; Kustas, W.P.; Massman, W.J. An evaluation of two models for estimation of the roughness height for heat transfer between the land surface and the atmosphere. J. Appl. Meteorol. 2001, 40, 1933-1951. [CrossRef]

49. Brutsaert, M. Evaporation into the Atmosphere: Theory, History and Applications; Springer: Hingham, MA, USA, 1982.

50. Nichols, W.E.; Cuenca, R.H. Evaluation of the evaporative fraction for parameterization of the surface energy balance. Water Resour. Res. 1993, 29, 3681-3690. [CrossRef]

51. Crago, R.; Brutsaert, W. Daytime evaporation and the self-preservation of the evaporative fraction and the Bowen ratio. J. Hydrol. 1996, 178, 241-255. [CrossRef]

52. Hoedjes, J.C.B.; Chehbouni, A.; Jacob, F.; Ezzahar, J.; Boulet, G. Deriving daily evapotranspiration from remotely sensed instantaneous evaporative fraction over olive orchard in semi-arid Morocco. J. Hydrol. 2008, 354, 53-64. [CrossRef]

53. Delogu, E.; Boulet, G.; Olioso, A.; Coudert, B.; Chirouze, J.; Ceschia, E.; le Dantec, V.; Marloie, O.; Chehbouni, G.; Lagouarde, J.-P. Reconstruction of temporal variations of evapotranspiration using instantaneous estimates at the time of satellite overpass. Hydrol. Earth Syst. Sci. 2013, 16, 2995-3010. [CrossRef]

54. Hurtado, E.; Sobrino, J.A. Daily net radiation estimated from air temperature and NOAA-AVHRR data: A case study for Iberian Penisula. Int. J. Remote Sens. 2001, 22, 1521-1533. [CrossRef]

55. Tian, H. Remote-Sensed Estimates of Evapotranspiration over A Complex Terrain of the Inland Hei River Basin; Cold and Arid Regions Environment and Engineering Research Insitute, Chinese Academy of Sciences: Lanzhou, China, 2008. (In Chinese)

56. Brunt, D. Physical and Dynamical Meteorology, 2nd ed.; Cambridge University Press: New York, NY, USA, 1939.

57. Carlson, T.N.; Ripley, D.A. On the relation between NDVI, fractional vegetation cover, and leaf area index. Remote Sens. Environ. 1997, 62, 241-252. [CrossRef]

58. Liang, S.L. Narrowband to broadband conversions of land surface albedo I: Algorithms. Remote Sens. Environ. 2001, 76, 213-238. [CrossRef]

59. Sobrino, J.A.; Caselles, V.; Becker, F. Significance of the remote sensed thermal infrared measurements obtained over a citrus orchard. ISPRS J. Photogramm. 1990, 44, 343-354. [CrossRef]

60. Valor, E.; Caselles, V. Mapping land surface emissivity from NDVI: Application to European, African and South American areas. Remote Sens. Environ. 1996, 57, 167-184. [CrossRef]

61. Duan, Q.Y.; Sorooshian, S.; Gupta, V. Effective and efficient global optimization for conceptual rain fall run off models. Water Resour. Res. 1992, 28, 1015-1031. [CrossRef]

62. Crow, W.T.; Wood, E.F. Impact of soil moisture aggregation on surface energy flux prediction during SGP'97. Geophys. Res. Lett. 2002, 29, 1008. [CrossRef]

63. Ronda, R.J.; van den Hurk, B.J.J.M.; Holtslag, A.A.M. Spatial heterogeneity of the soil moisture content and its impact on surface flux densities and near-surface meteorology. J. Hydrometeorol. 2002, 3, 556-570. [CrossRef] 
64. He, L.; Ivanov, V.Y.; Bohrer, G.; Maurer, K.D.; Vogel, C.S.; Moghaddam, M. Effects of fine-scale soil moisture and canopy heterogeneity on energy and water fluxes in a northern temperate mixed forest. Agric. For. Meteorol. 2014, 184, 243-256. [CrossRef]

65. Xu, T.R.; Liu, S.M.; Lu, X.; Chen, Y.J.; Jia, Z.Z.; Xu, Z.W.; Nielson, J. Temporal upscaling and reconstruction of thermal remotely sensed instantaneous evapotranspiration. Remote Sens. 2015, 7, 3400-3425. [CrossRef]

66. Guerschman, J.P.; van Dijk, A.I.J.M.; Mattersdorf, G.; Beringer, J.; Hutley, L.B.; Leuning, R.; Pipunic, P.C.; Sherman, B.S. Scaling of potential evapotranspiration with MODIS data reproduces flux observations and catchment water balance observations across Australia. J. Hydrol. 2009, 369, 107-119. [CrossRef]

(C) 2015 by the authors; licensee MDPI, Basel, Switzerland. This article is an open access article distributed under the terms and conditions of the Creative Commons by Attribution (CC-BY) license (http://creativecommons.org/licenses/by/4.0/). 